\title{
ОЦЕНКА СИТУАЦИИ РЕГИОНАЛЬНОГО ФИНАНСИРОВАНИЯ В СФЕРЕ ОКАЗАНИЯ МЕДИЦИНСКИХ УСЛУГ "
}

\author{
(c) 2020 Музалёв Сергей Владимирович \\ кандидат экономических наук, доцент департамента бизнес-аналитики \\ Финансовый университет при Правительстве РФ, Россия, Москва \\ E-mail: SVMuzalyov@fa.ru
}

(c) 2020 Гаврилов Дмитрий Викторович

заместитель начальника отдела бюджетной политики в сфере просвещения Департамента бюджетной политики в социальной сфере и науке Министерства финансов Российской Федерации Министерство финансов Российской Федерации, Россия, Москва

E-mail: gdv2012@bk.ru

Преобразования начала 90-х годов прошлого столетия в части экономики и политики, снижение финансовой защиты негативно отразились на здоровье населения. Трансформация сектора здравоохранения в виду изменений 1990-х годов в России обусловили ряд неблагоприятных последствий, в том числе и недостаточный доступ к медицинскому обслуживанию и финансовой защите населения нашего государства. Последующий экономический рост, сокращение бедности и политические обязательства по улучшению охвата привели к постепенному улучшению, в части медицинского обслуживания и финансирования пожилого населения, но с задержкой во времени.

Период 1998 года ознаменован серьезными экономическими проблемами, сформированными кризисом и политической слабостью, что негативным образом отразилось на потенциале системы здравоохранения Российской Федерации.

Крупные инвестиции и реформы, связанные с программой государственных гарантий, в течение 2000-х годов способствовали достижению прогресса в области здравоохранения и смягчили изменение тенденций во время финансового кризиса. Фискальное перераспределение было использовано для увеличения распределения ресурсов в менее обеспеченных субъектах. Увеличение государственных расходов на больничную помощь помогло улучшить доступ к стационарной помощи для бедных, особенно пожилых людей. Увеличение инвестиций в диагностику, оборудование в амбулаторно-поликлинических учреждениях расширяет доступ к данным услугам, однако в основном эти услуги доступны в крупных городах.

Ведущие мировые страны проводят реформирование системы здравоохранения, ориентируясь на современные цели и задачи общества, а также интересы населения страны. Вводятся правила по включению услуг страхования в здравоохранении, что определяет важность вопросов государственного финансирования в сфере оказания медицинских услуг. Процесс контролируется с помощью индикаторов оценки достижений в области защиты от финансовых рисков и доступа к качественным основным медицинским услугам.

Ключевые слова: государство, медицинские услуги, расходы, регионы, система здравоохранения, реформирование, финансирование.

Проблема, стоящая перед российской системой здравоохранения, заключается в относительной нехватке средств государственного сектора. Есть разрыв между обязательствами в части необходимого финансирования лекарственного обеспечения здравоохранения.

Лекарства теоретически предоставляются больничным пациентам бесплатно, но амбулаторные больные должны платить за них, хотя амбулаторные лекарства должны быть покрыты для специальной группы бенефициаров $(16,9$ млн. человек) в Федеральной программе «Программа дополнительного лекарственного обеспечения». Однако проблема состоит в том, что бенефициары должны платить за то, что они должны получить бесплатно.

Методология исследований в области медико-демографической ситуации и оказа-

* Исследование выполнено в рамках научного проекта ГПХ ВТК-ГЗ-ПИ-22-20 «Прогностическая оценка объемов медицинской помощи пожилым людям» 
ния медицинских услуг определяет важность вопросов современного общества. В качестве теоретическо-методологической основы проведенного исследования выступают научные труды ведущих специалистов в данной области, а именно: Н.Н.Калмыкова, Н.Н.Логиновой и Н.В.Харчиковой [1], Л.А.Саруханян [2], Е. М. Щербаковой [3] и др.

Неформальное распределение расходов широко распространено в больничном секторе. Поэтому предполагается, что значительная доля спроса на фармацевтические препараты в Российской Федерации просто остается неудовлетворенной. Все вышеизложенное подразумевает, что медицинские льготы в рамках системы обязательного медицинского страхования в Российской Федерации должны быть пересмотрены, чтобы избежать невыполнимых обязательств и обеспечить стимулы для выбора более дорогой медицинской помощи.

Анализируя ситуацию в федеральных округах на 1 января 2019 года, выделим следующие данные по доле пожилых граждан в общем составе населения (от наибольшего значения к наименьшему значению) (см. рисунок 1) [8].

Согласно данным Росстата, в России из 146,7 млн. человек 37,9 млн. человек в 2018 г. - это население старше трудоспособного возраста, что составляя 25,4\% от общей численности населению нашей страны. Также численность лиц в возрасте 65 лет и старше, по сравнению с 2017 годом, увеличилась на 2,8\% (с 20,8 млн. чел.до 21,4 млн. чел.).

Помимо общего числа пожилых людей по отношению к трудоспособному населению, интересным фактом является то, что самым старым по среднему возрасту своих граждан является Центральный Федеральный округ, а самым молодым Дальневосточный Федеральный округ. Анализ доли пожилых граждан в общем составе населения по регионам внутри федеральных округов Российской Федерации показал, что самый высокий средний возраст населения имеет
Тульская область - 42,96, а самый низкий - Чеченская Республика - 28,2 [8].

Еще одной важной особенностью регионов является разница в общей продолжительности жизни населения. «Так, самые высокие показатели по продолжительности жизни на протяжении многих лет удерживают республики Северного Кавказа - 76,6 лет на 2019 год» [5].

Если же исследовать федеральные округа в целом, то здесь также наблюдается лидерство Северо-Кавказского Федерального округа, причем, для обоих гендеров (мужчин и женщин). Второе место по праву занимает Центральный Федеральный округ, на третьем и четвертом месте Южный и Северо-Западный Федеральные округа, на пятом месте Дальневосточный Федеральный округ. В определенном смысле на продолжительность жизни по округам во многом влияют климатические условия, однако, если мы рассматриваем отдельно взятый федеральный округ, то продолжительность жизни будет определяться в большей степени по социальноэкономической обстановке, уровню жизни, доступности образования и медицины, наличием в регионе вредного промышленного производства и т.д. И здесь снова лидером становятся Северо-Кавказские республики - «Ингушетия 83,4 года, Дагестан - 79,1 и замыкает тройку лидеров город Москва - 78,3 года» [5].

Важным показателем при определении динамики доли пожилых граждан в общем составе населения является информация о соотношении мужской и женской продолжительности жизни по регионам: «на конец 2018 года в среднем по Российской Федерации она составляет 10,07 лет (женщины живут дольше). Наименьший разрыв по сроку жизни имеют Республика Ингушетия $(6,1)$, Дагестан $(5,5)$ и Чечня - $(4,6)$ лет, самый большой разрыв зафиксирован в Ненецком Автономном округе - почти 13 лет» [5]. Таким образом, с учетом специфики смертности в нашей стране и продолжительностью жизни формируются целые возрастные категории, состоящие в

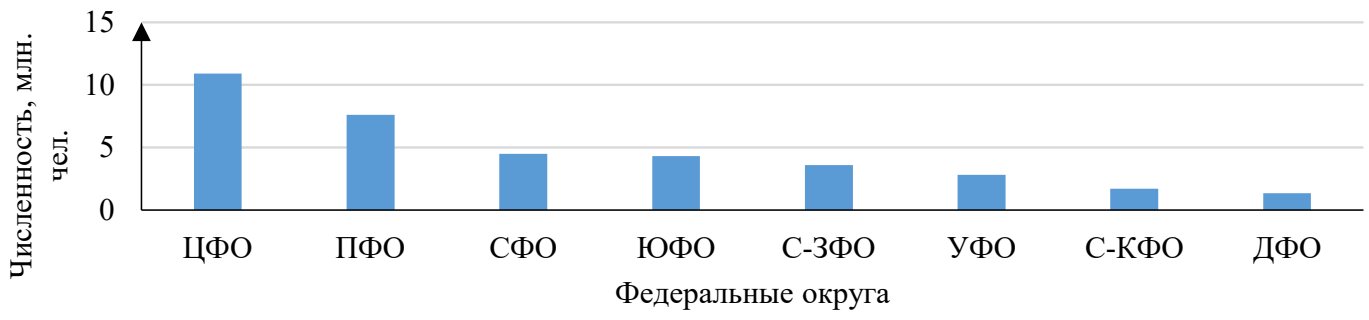

Рисунок 1. Распределение численности пожилых граждан по федеральным округам по состоянию на 1 января 2019 года, млн. чел. (составлено авторами по данным Росстата [6]) 
основном из женщин.

В 2019 году динамика смертности населения страны показала сокращение, о чем свидетельствуют данные Росстата РФ. Средняя ожидаемая продолжительность жизни при рождении для мужчин составляет 67,77 лет, для женщин - 77,83 года. Динамика смертности населения страны, возраст которых выше трудоспособного уровня в период 2013-2019 гг. представлена на рисунке 2.

Данные Министерства здравоохранения Российской Федерации свидетельствуют о том, что в целом по Российской Федерации заболеваемость на начало 2019 года повысилась до уровня 202603,7 тыс. человек (в 2017 году 199962,2) сре- ди населения старше трудоспособного возраста.

Региональное финансирование в сфере оказания медицинских услуг проводится через ряд пилотных проектов. Пилотные проекты системы долговременного ухода в 2019 году получили свой старт в 12 регионах: Республик Мордовия, Татарстан; Волгоградской, Кемеровской, Кировской, Костромской, Новгородской, Рязанской, Тульской областях; в Камчатском и Ставропольском крае; в г. Москва. «В 85 субъектах Российской Федерации с 2019 по 2022 год нарастающим итогом внедряется система долговременного ухода» [7] (см. рисунок 3).

Система долговременного ухода успешно

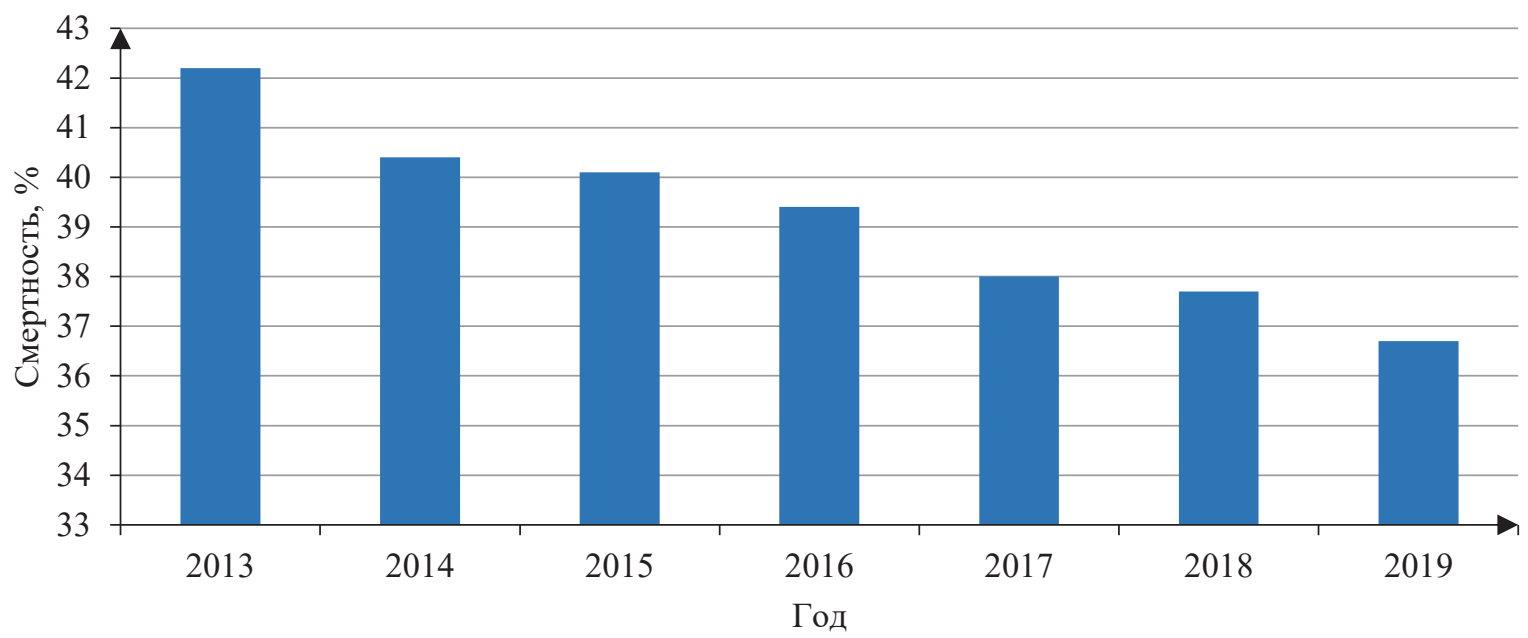

Рисунок 2. Динамика смертности населения страны, возраст которых выше трудоспособного уровня в период 2013-2019,\% (составлено авторами по данным Росстата [6])

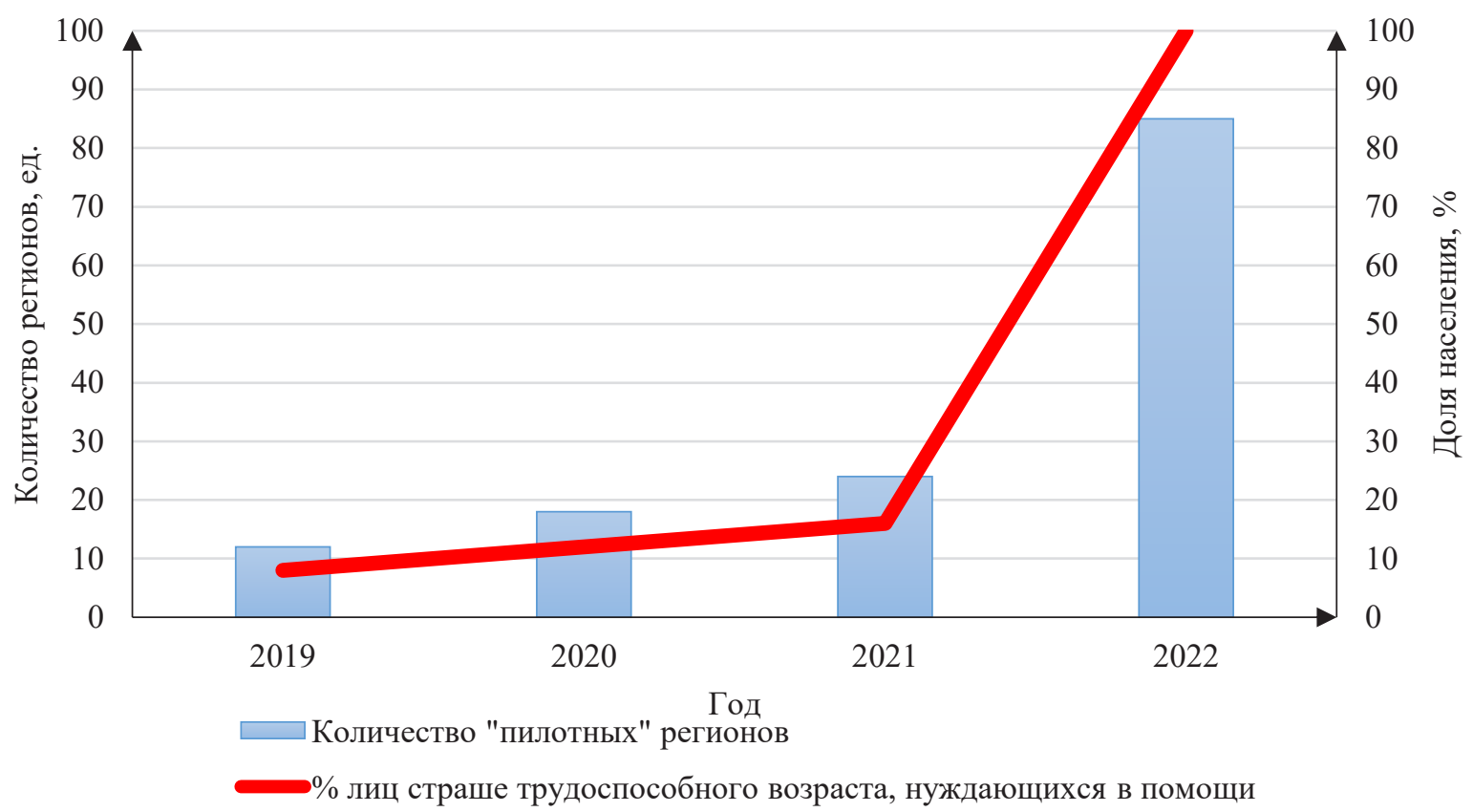

Рисунок 3. Нарастающий итог внедрения системы долговременного ухода за пожилым населением (составлено авторами по данным источника [7]) 


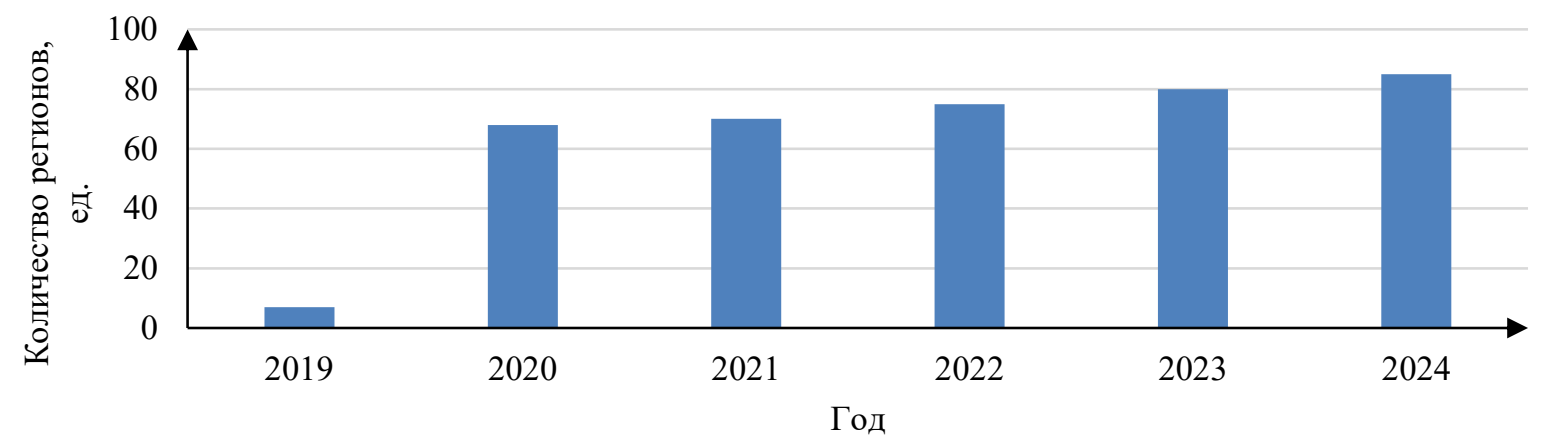

Рисунок 4. Динамика количества регионов, реализующих комплекс профилактических мер и ранее выявление когнитивных нарушений у лиц пожилого и старческого возраста (составлено авторами по данным источника [7])

внедряется во многих регионах нашей страны, обеспечивая при этом поддержку каждому человеку, имеющему дефицит самообслуживания или полностью утратившему способность самостоятельного ухода и независимости. Текущее и прогнозное количество регионов, занятых реализацией комплекса мер, направленных на профилактику и раннее выявление когнитивных нарушений у лиц пожилого и старческого возраста, представлено на рисунке 4.

В заключении статьи отметим, что данные статистики по регионам позволяют сделать вывод о том, что процесс старения населения в стране не является равномерным и определяется, с одной стороны, показателями рождаемости, но также важно учитывать и такой фактор, как рост продолжительности жизни в ряде регионов Российской Федерации и снижение продолжительности жизни в других регионах. То есть для каждого из регионов Российской Федерации старение наступает разный возрастной период, который имеет свой собственный порог.

\section{Библиографический список}

1. Калмыков Н.Н., Логинова Н. Н. и Харчикова Н. В. О демографической ситуации в России: анализ, проблемы и перспективы развития // Актуальные проблемы современности: наука и общество - 3/2018. - С. 3-13

2. Саруханян Л.А. Проблемы института брака в Российской Федерации // Международный журнал прикладных и фундаментальных исследований. - 2016. - № 11-4.- С. 775-777.

3. Чувашова М.Н. Оценка качества экономического пространства региона сырьевой направленности: диссертация ... кандидата экономических наук: 08.00.05 Чувашова Мария Николаевна: Красноярск. 2016. 235 с.

4. Щербакова E.M. Россия: предварительные демографические итоги 2017 года (часть I) //Демоскоп Weekly. 2018. № 759-760. [Электронный ресурс]. Режим доступа: URL: http://demoscope.ru/weekly/2017/0759/ barom01.php.

5. Сайт о странах, городах, статистике населения и пр. Население России: численность, динамика, статистика http://www.statdata.ru/russia.

6. Сайт Федеральной службы государственной статистики. https://www.gks.ru/folder/13877.

7. Система долговременного ухода медицинская составляющая https://docviewer.yandex.ru/view/0/?page=28\& *=2C8MlonSJ63hSzj90eLiJ7MqfU97InVybCI6Imh0dHBzOi8vcHJpaWxtZW5pZS5ub3Yuc29jaW5mby5ydS9tZWRp YS8yMDE5LzA4LzEzLzEyNjM3 (дата обращения 10.09.2020).

8. Статистика по России. Средний возраст https://russia.duck.consulting/maps/10. 